\title{
The problem of accuracy in dietary surveys. Analysis of the over 65 UK National Diet and Nutrition Survey
}

\author{
Adrian Cook, Jane Pryer, Prakash Shetty
}

\begin{abstract}
Study objective-To investigate the prevalence and nature of low energy reporting in a dietary survey of British adults over 65 years of age.

Design-Randomly selected cross sectional sample of 2060 British adults over 65 years. Four day weighed food diaries and questionnaires on health, lifestyle and socioeconomic characteristics.

Setting-Great Britain.

Participants-539 women and 558 men over 65 years who were free living and completed four day food diaries.

Main results-A high proportion of men and women were classified as low energy reporters (LERs). Reported consumption of full fat dairy products, sugar and sweet foods, and alcoholic drinks differed most between LERs and non-LERs. Among LERs, reported protein and starch intakes were higher, fat, sugar and alcohol intakes were lower. LERs of either sex were more likely to be obese, male LERs were also more likely to belong to the manual social classes.

Conclusions-The high level of low energy reporting probably resulted from a coalescence of factors such as the weighed diary methodology and a reluctance to report consumption of unhealthy foods. The use of validatory biomarkers such as doubly labelled water needs to be more widespread.
\end{abstract}

(F Epidemiol Community Health 2000;54:611-616)

A major problem in self reported dietary studies is people who under-report their true habitual food intake, or change their diet, during the period of the survey. ${ }^{12}$ The result is participants with energy intakes seemingly lower than that required for long term energy balance, known as low energy reporters (LERs). Little is known about the precise nature of the problem, but the limited evidence available to date has suggested that low energy reporting does not affect foods or nutrients uniformly, and is also more likely to occur in certain subjects than others. In a previous survey of the UK adult population the reported consumption of biscuits, cakes and pastries differed most strongly between those defined as low energy reporters and other participants. ${ }^{3}$ In dietary validation studies, subjects found to under-report their protein intakes also had lower intakes of fat, energy and sugar, but not starch, fibre or alcohol when compared with other participants. ${ }^{4}$ Low energy reporting has also been shown to be more prevalent among obese participants, those who smoke, or members of the manual social classes. ${ }^{35}$ Two similar Finnish studies 10 years apart also raised the question of low energy reporting being an increasing problem. ${ }^{6}$

Pryer $^{3}$ explored low energy reporting in the adult British population using data from the National Diet and Nutrition Survey (NDNS) of those aged 16-64 years. In this study we have investigated low energy reporting in a survey of the more elderly population, using data from the NDNS of the British population over 65 years of age, a separate survey using similar methodology. We have investigated the extent and nature of low energy reporting, our aims being firstly to quantify the number of men and women reporting levels of food intake incompatible with long term energy balance, and secondly to characterise them in terms of their food and nutrient intakes, and sociodemographic characteristics.

\section{Methods}

The National Diet and Nutrition Survey of people over 65 years of age comprised 1632 free living people and 428 subjects living in institutions. Briefly, the survey was commissioned by the Ministry of Agriculture, Fisheries and Foods (MAFF) and the Department of Health, and undertaken collaboratively with University College London and the Dunn Nutrition Unit, Cambridge. Fieldwork was carried out in four waves of 10-12 weeks each, between October 1994 and September 1995. The free living sample was recruited using a multi-stage clustered design. The postal address file was used as the sampling frame, with 80 postal sectors being selected as first stage units, probability of selection being proportional to size. From each sector, 375 households were randomly selected and sent a sift form to identify those households containing an eligible adult. A random sample of eligible adults was then taken, with no more than one subject from each household and probability of selection weighted by age to obtain reasonable numbers from the oldest age groups.

Preliminary analysis revealed that the level of low energy reporting among free living respondents was much higher than that seen among the institutionalised sample. This study therefore uses only the free living sample, which comprises approximately $80 \%$ of the total.

Study participants were issued with calibrated dietary scales and asked to keep a 
Table 1 Socioeconomic, behavioural, health and demographic characteristics of men and women LERs and non-LERs

\begin{tabular}{|c|c|c|c|c|c|c|}
\hline \multirow[b]{3}{*}{ Age, (mean years, SEM) } & \multicolumn{3}{|l|}{ Men } & \multicolumn{3}{|l|}{ Women } \\
\hline & $\begin{array}{l}L E R \\
(n=163)\end{array}$ & $\begin{array}{l}\text { non-LER } \\
(n=395)\end{array}$ & \multirow{2}{*}{$\frac{p}{0.61}$} & $\begin{array}{l}L E R \\
(n=260)\end{array}$ & $\begin{array}{l}\text { non-LER } \\
(n=279)\end{array}$ & \multirow{2}{*}{$\frac{p}{0.38}$} \\
\hline & $76 \quad(0.6)$ & $76 \quad(0.3)$ & & $(0.5)$ & $(0.5)$ & \\
\hline Current smoker (\%) & 24 & 24 & 0.96 & 17 & 15 & 0.48 \\
\hline Living alone $(\%)$ & 30 & 24 & 0.16 & 58 & 58 & 0.99 \\
\hline \multicolumn{7}{|l|}{ Socioeconomic characteristics } \\
\hline Manual social class (\%) & 64 & 49 & $<0.01$ & 55 & 42 & $<0.01$ \\
\hline Receiving benefits (\%) & 44 & 34 & 0.04 & 59 & 44 & $<0.01$ \\
\hline \multicolumn{7}{|l|}{ Education: } \\
\hline None (\%) & 60 & 48 & & 77 & 67 & \\
\hline Ordinary $(\%)$ & 27 & 31 & & 13 & 19 & \\
\hline Higher (\%) & 13 & 21 & 0.03 & 10 & 14 & 0.04 \\
\hline Home owner (\%) & 76 & 81 & 0.19 & 74 & 78 & 0.24 \\
\hline Private pension (\%) & 71 & 75 & 0.37 & 42 & 44 & 0.65 \\
\hline \multicolumn{7}{|l|}{ Health status } \\
\hline \multicolumn{7}{|l|}{ Health: } \\
\hline Good (\%) & 55 & 68 & & 62 & 70 & \\
\hline Fair $(\%)$ & 36 & 27 & & 32 & 28 & \\
\hline Poor $(\%)$ & 9 & 5 & $<0.01$ & 7 & 3 & 0.03 \\
\hline Mobility problems (\%) & 32 & 22 & 0.01 & 35 & 25 & 0.02 \\
\hline Chewing problems (\%) & 15 & 13 & 0.45 & 15 & 16 & 0.73 \\
\hline BMI (mean, SEM) & $27.5(0.3)$ & $25.7(0.2)$ & $<0.01$ & $27.9(0.3)$ & $25.4(0.3)$ & $<0.01$ \\
\hline \multicolumn{7}{|l|}{ Area of residence (\%) } \\
\hline North & 31 & 23 & & 23 & 24 & \\
\hline Midlands & 20 & 26 & & 24 & 21 & \\
\hline South & 32 & 39 & & 38 & 41 & \\
\hline Wales & 8 & 5 & & 7 & 5 & \\
\hline Scotland & 9 & 8 & 0.11 & 9 & 9 & 0.47 \\
\hline
\end{tabular}

weighed record of all food consumed over four consecutive days. Measurements were made of body weight, height, demi-span, mid-upper arm circumference, waist and hip circumference. An interviewer administered questionnaire collected data on: age, sex, social class, income, pensions and benefits, geographical area of residence, cigarette smoking and household composition.

Of the 1632 subjects in the free living sample 357 did not complete four day diaries and were excluded from the analysis. A further 178 were excluded as their body weight was not recorded, preventing calculation of basal metabolic rate (BMR). Of the remaining 1097 subjects, 539 were women and 558 were men. All subjects were non-dieting at the time of the survey.

BMR was calculated for each subject from their body weight, age and sex, using age and gender specific equations. ${ }^{7}$ These equations are suitable for the British population and differentiate between those aged more than 75 years

Table 2 Multivariate analysis of factors predictive of LER status, by sex

\begin{tabular}{|c|c|c|c|c|c|c|}
\hline & \multicolumn{3}{|c|}{$\operatorname{Men}(n=505)$} & \multicolumn{3}{|c|}{ Women $(n=436)$} \\
\hline & $\begin{array}{l}\text { Odds } \\
\text { ratio }\end{array}$ & SEM & $p$ & $\begin{array}{l}\text { Odds } \\
\text { ratio }\end{array}$ & SEM & $p$ \\
\hline Living alone & 1.12 & 0.33 & 0.69 & $\star$ & & \\
\hline Manual social class & 1.93 & 0.53 & 0.02 & 1.45 & 0.36 & 0.14 \\
\hline Receiving benefits & 1.04 & 0.29 & 0.88 & 1.16 & 0.28 & 0.54 \\
\hline \multicolumn{7}{|l|}{ Educationt: } \\
\hline Ordinary & 0.85 & 0.24 & 0.58 & 1.07 & 0.33 & 0.83 \\
\hline Higher & 0.5 & 0.19 & 0.07 & 1.01 & 0.35 & 0.99 \\
\hline Home owner & 0.54 & 0.17 & 0.05 & 0.67 & 0.17 & 0.11 \\
\hline \multicolumn{7}{|l|}{ Health $\ddagger$ : } \\
\hline Fair & 1.11 & 0.31 & 0.72 & 1.18 & 0.29 & 0.5 \\
\hline Poor & 1.2 & 0.58 & 0.71 & 2.81 & 1.63 & 0.07 \\
\hline Mobility problems & 0.65 & 0.21 & 0.18 & 0.85 & 0.21 & 0.5 \\
\hline Obese & 3.67 & 1.16 & 0.00 & 2.31 & 0.63 & 0.00 \\
\hline \multicolumn{7}{|l|}{ Area\$: } \\
\hline Midlands & 0.61 & 0.21 & 0.15 & $\star$ & & \\
\hline South & 0.78 & 0.25 & 0.43 & & & \\
\hline Wales & 1.41 & 0.66 & 0.47 & & & \\
\hline Scotland & 1.01 & 0.44 & 0.98 & & & \\
\hline Baseline odds & 0.59 & 0.42 & 0.37 & 0.78 & 0.31 & 0.5 \\
\hline
\end{tabular}

*Univariate $\mathrm{p}>0.25$ for living alone and area of residence among women. $\dagger$ Baseline - no education beyond 14 years. $\ddagger$ Baseline - in good health. $₫$ Baseline - North of England. and those aged $65-75$. The within subject coefficient of variation of daily reported energy intake was $17.6 \%$, giving a cut off 2 value of 1.1 using the Goldberg formula ${ }^{8}$ with $95 \%$ confidence limits. Multiplying the cut off 2 value by BMR gives a level of energy intake considered to be the lowest plausible amount for a non-dieting person during the period of the study. LERs were thus defined as those subjects reporting an average daily energy intake over four days below $1.1 \times$ BMR.

Total food and drink consumption was divided between 29 food/drink groups and associations between LER status and group consumption were examined. Consumption distributions were positively skewed in most groups, however the skewness was generally the result of high consumption by a very small number of people and the mean remained an informative descriptive statistic. LERs were formally compared with non-LERs by Mann-Whitney nonparametric tests. Distributions of nutrient intake were generally closer to normality and $t$ tests were used to test associations between reported nutrient intake and LER status.

Univariate associations between social, economic and demographic variables were examined using $\chi^{2}$ tests and $t$ tests. A multivariate analysis was then carried out, in which those variables for which the univariate association exceeded $\mathrm{p}=0.25$ were entered into a logistic regression model. All analysis was done using Stata software.

\section{Results}

The average energy:BMR ratio of the survey participants was $1.13(\mathrm{SD}=0.3)$ for women and $1.25(0.3)$ for men. Two hundred and sixty women (48\%) and 163 men (29\%) fell below the cut off level of 1.1 and were classified as LERs. The difference in proportions of LERs between the sexes was highly significant 
Table 3 Grouped food/drink consumption ( $g$ or ml daily), by sex and low energy reporter (LER) status

\begin{tabular}{|c|c|c|c|c|c|c|c|c|c|}
\hline \multirow[b]{3}{*}{ rice/pasta } & \multicolumn{5}{|l|}{ Men } & \multicolumn{4}{|c|}{ Women } \\
\hline & \multicolumn{2}{|c|}{$\begin{array}{l}\text { non-LER }(n=279) \\
\text { mean }(S E M)\end{array}$} & \multicolumn{2}{|c|}{$\begin{array}{l}\text { LER }(n=260) \\
\text { mean }(S E M)\end{array}$} & \multirow{2}{*}{$\begin{array}{l}p \\
0.21\end{array}$} & \multicolumn{2}{|c|}{$\begin{array}{l}\text { non-LER }(n=394) \\
\text { mean }(S E M)\end{array}$} & $\begin{array}{l}\text { LER }(n=164) \\
\text { mean }(S E M)\end{array}$ & \multirow{2}{*}{$\begin{array}{l}p \\
0.17\end{array}$} \\
\hline & 12 & (1.3) & 12 & $(2.4)$ & & 10 & (1.5) & $9.0(1.7)$ & \\
\hline white bread/unrefined cereals & 76 & (3) & 68 & (4) & 0.46 & 55 & (3) & $46 \quad(2.5)$ & 0.10 \\
\hline brown bread/wholegrain cereals & 102 & (6) & 54 & (6) & 0.00 & 72 & (4) & $(3.1)$ & 0.00 \\
\hline biscuits/cakes/pastries & 116 & (4) & 62 & (4) & 0.00 & 97 & (4) & (3) & 0.00 \\
\hline whole milk/cream & 141 & (9) & 83 & (9) & 0.00 & 148 & (10) & (8) & 0.00 \\
\hline low fat milk/yoghurt & 142 & (9) & 119 & (11) & 0.28 & 133 & (11) & (10) & 0.91 \\
\hline cheese & 15 & $(0.8)$ & & $(1.0)$ & 0.00 & 10 & $(0.7)$ & $6.5(0.6)$ & 0.00 \\
\hline eggs & 21 & $(1.3)$ & 16 & $(1.5)$ & 0.03 & 15 & (1.1) & $11 \quad(1.0)$ & 0.01 \\
\hline butter & 7.2 & $(0.6)$ & & $(0.6)$ & 0.00 & & $(0.7)$ & $4.4(0.5)$ & 0.00 \\
\hline polyunsaturated spreads & 13 & $(0.7)$ & & $(0.8)$ & 0.02 & & $(0.6)$ & $7.6(0.6)$ & 0.11 \\
\hline other spreads & 1.7 & $(0.3)$ & & $(0.2)$ & 0.29 & 1.2 & $(0.3)$ & $0.7(0.2)$ & 0.10 \\
\hline bacon/ham & 18 & $(1.0)$ & 14 & $(1.2)$ & 0.14 & 11 & $(0.8)$ & $11 \quad(1.0)$ & 0.34 \\
\hline beef/veal & 29 & $(2.2)$ & 27 & (3.3) & 0.42 & 29 & $(2.5)$ & $(2.4)$ & 0.05 \\
\hline lamb/pork & 20 & (1.6) & 14 & $(1.9)$ & 0.03 & 13 & (1.4) & $(1.5)$ & 0.71 \\
\hline poultry & 20 & (1.6) & 21 & (2.7) & 0.80 & 20 & (1.7) & $(2.1)$ & 0.27 \\
\hline meat products & 45 & (2.4) & 34 & $(2.3)$ & 0.05 & 29 & $(2.0)$ & $(1.8)$ & 0.05 \\
\hline fried fish & 14 & $(1.2)$ & 15 & $(1.8)$ & 0.71 & 13 & $(1.1)$ & $(1.1)$ & 0.16 \\
\hline other fish & 21 & (1.5) & 19 & (2.3) & 0.26 & 16 & (1.3) & $(1.5)$ & 0.90 \\
\hline vegetables & 213 & (6) & 176 & (7) & 0.00 & 175 & (6) & 166 & 0.23 \\
\hline fried potatoes & 37 & (2.2) & 26 & (2.6) & 0.01 & 30 & $(2.0)$ & (1.6) & 0.00 \\
\hline fruit/nuts & 112 & (5) & 65 & (6) & 0.00 & 98 & (5) & (6) & 0.14 \\
\hline sugar & 39 & (1.6) & 22 & (1.8) & 0.00 & 27 & (1.5) & $(1.0)$ & 0.00 \\
\hline fruit juice & 26 & (2.9) & 14 & (3.4) & 0.00 & 27 & (3.7) & (2.6) & 0.11 \\
\hline soft drinks & 50 & $(6.0)$ & 42 & $(6.9)$ & 0.80 & 46 & (6.3) & $48 \quad(6.4)$ & 0.59 \\
\hline wine/spirits & 36 & (4.4) & 9. & $(2.0)$ & 0.00 & 22 & (2.7) & $7.8(1.4)$ & 0.00 \\
\hline beer/lager & 201 & (21) & 103 & (26) & 0.00 & 22 & (5.4) & $11 \quad(4.0)$ & 0.02 \\
\hline tea/coffee & 870 & (20) & 782 & (29) & 0.01 & 754 & (18) & (18) & 0.04 \\
\hline soup & 34 & (3.3) & 34 & $(5.2)$ & 1.00 & 32 & (3.2) & (3.7) & 0.02 \\
\hline sauces/pickles & 23 & $(1.2)$ & 15 & (1.6) & 0.00 & 19 & (1.2) & $(1.2)$ & 0.00 \\
\hline
\end{tabular}

$(\mathrm{p}<0.001)$, therefore all subsequent analyses were performed separately by sex.

SOCIOECONOMIC, DEMOGRAPHIC AND BEHAVIOURAL CHARACTERISTICS

There were a number of significant differences between the LERs and the non-LERs in both sexes (table 1). For both men and women, the LERs were more likely to come from the manual social classes ( $64 \% v 49 \%$ among men, $55 \%$ v $42 \%$ among women). They were also more likely to be in receipt of benefits and more likely to report physical mobility problems, defined as needing aids to walk. The LERs of either sex were less likely to report being in good health and less likely to have received higher education. Body mass index was also significantly higher among the LERs of both sexes (27.5 $v 25.7$ among men, $27.9 v 25.4$ among women). No significant differences were observed in age, smoking habits, numbers living alone, home ownership, receipt of private pensions, problems in chewing food or geographical area of residence.

Multiple logistic regression models showed that among men obesity (body mass in$d e x \geqslant 30$ ), social class and home ownership

Table 4 Percentage contribution of food/drink groups to total energy, by sex and LER status

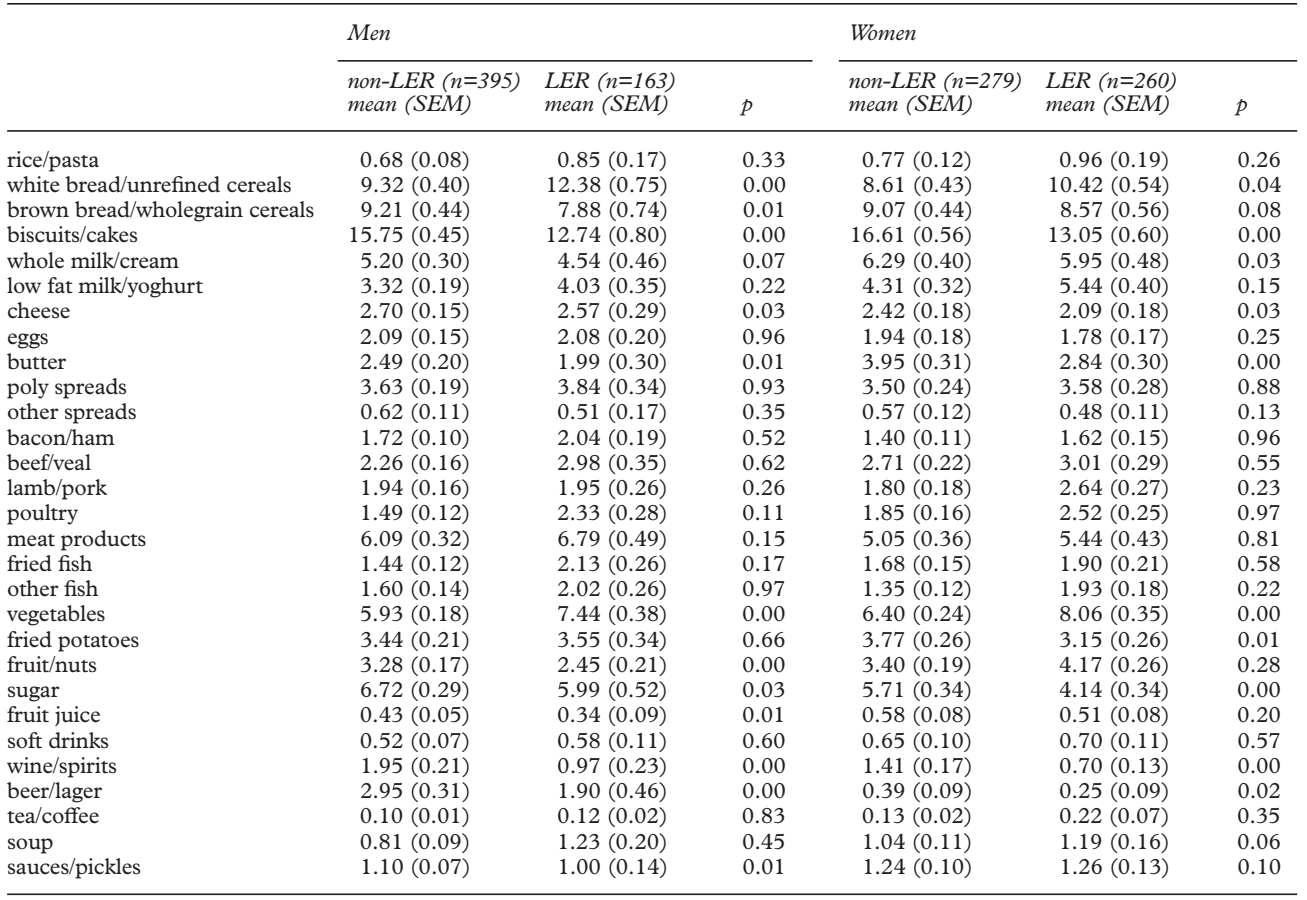


were all independently associated with LER status at the $95 \%$ significance level, while among women only obesity remained significant (table 2). There was also some evidence of education among men and health among women being associated with LER status, the probability decreasing with education and increasing with poor health.

REPORTED FOOD INTAKE

A comparison of the reported food intake of LERs and non-LERs is provided in table 3. A similar comparison with food intake expressed as a percentage of total energy intake is presented in table 4.

Male LERs reported lower consumption than non-LERs of 25 food/drink groups, the largest proportional differences arising with alcohol, butter, non-low fat spreads, fruit juice, wholemeal bread, biscuits, cakes and pastries (table 3). The differences reached statistical significance $(\mathrm{p}<0.05)$ for 17 groups. Women generally reported lower intakes than men, and LERs reported less than non-LERs in all but five food/drink groups. The differences reached statistical significance in 13 groups with the largest proportionate differences arising in consumption of alcohol, butter, sugar and biscuits, cakes and pastries.

Adjusting for energy intake, male LERs reported higher intakes in 16 food/drink groups, the largest differences occurring with poultry, soup and fried fish (table 4). The 13 food/drink groups for which male LERs reported lower intakes included full fat dairy products, biscuits, cakes and pastries, fruit and
KEY POINTS

- Low energy reporting is a major problem in dietary surveys.

- Several different factors are responsible.

- Low energy reporting does not affect foods or nutrients uniformly.

- Prevalence of low energy reporting differs between socioeconomic groups.

nuts, alcohol and fruit juice. Female LERs reported higher intakes of 17 food/drink groups and lower intakes of 12 groups. The food/drink groups reported higher by male LERs were exactly the same as those reported higher by female LERs with the exception of sauces and pickles.

\section{NUTRIENT INTAKE}

Over the four day period the average daily intakes of energy, macronutrients, eight minerals and 12 vitamins were significantly lower $(p<0.01)$ for LERs compared with non-LERs of either sex (results not shown). For macronutrient densities (intakes as \% total energy or per $1000 \mathrm{kcal}$ ), significantly higher intakes of protein and starch were reported by LERs of both sexes, as were significantly lower intakes of alcohol, total fat, saturated fat and transaturated fat (table 5). In addition, sugar intake was lower and fibre intake higher among both sexes, although differences were not statistically significant. The largest observed differences were the increased protein intakes of

Table 5 Reported macro and micronutrient density, by sex and LER status

\begin{tabular}{|c|c|c|c|c|c|c|c|c|}
\hline & \multicolumn{4}{|l|}{ Men } & \multicolumn{4}{|l|}{ Women } \\
\hline & $\begin{array}{l}\text { non-LER }(n=394) \\
\text { mean }(S E M)\end{array}$ & $\begin{array}{l}\text { LER }(n=164) \\
\text { mean }(S E M)\end{array}$ & $\% *$ & $p$ & $\begin{array}{l}\text { non-LER }(n=279) \\
\text { mean }(S E M)\end{array}$ & $\begin{array}{l}\text { LER }(n=260) \\
\text { mean }(S E M)\end{array}$ & $\% *$ & $p$ \\
\hline \multicolumn{9}{|l|}{$\%$ energy } \\
\hline protein & $14.5(0.13)$ & $16.7(0.3)$ & 115 & 0.00 & $14.8(0.16)$ & $17.2(0.3)$ & 116 & 0.00 \\
\hline carbohydrate & $45.9(0.34)$ & $46.8(0.6)$ & 102 & 0.19 & $46.1(0.34)$ & $46.7(0.4)$ & 101 & 0.27 \\
\hline alcohol & $4.1(0.33)$ & $2.5(0.5)$ & 61 & 0.01 & $1.5(0.17)$ & $0.9(0.1)$ & 60 & 0.01 \\
\hline fat & $35.4(0.28)$ & $33.9(0.5)$ & 96 & 0.01 & $37.7(0.34)$ & $35.3(0.4)$ & 94 & 0.00 \\
\hline saturfat & $14.7(0.18)$ & $13.8(0.3)$ & 94 & 0.01 & $16.3(0.24)$ & $14.9(0.3)$ & 91 & 0.00 \\
\hline transfat & $1.5(0.02)$ & $1.4(0.0)$ & 93 & 0.04 & $1.7(0.03)$ & $1.5(0.0)$ & 92 & 0.01 \\
\hline mono & $10.9(0.10)$ & $10.6(0.2)$ & 97 & 0.15 & $11.3(0.12)$ & $10.7(0.2)$ & 94 & 0.00 \\
\hline n3poly & $0.8(0.02)$ & $0.8(0.0)$ & 100 & 0.92 & $0.8(0.02)$ & $0.9(0.0)$ & 109 & 0.04 \\
\hline n6poly & $4.9(0.11)$ & $4.8(0.2)$ & 98 & 0.65 & $4.9(0.13)$ & $4.8(0.2)$ & 97 & 0.42 \\
\hline poly & $5.7(0.11)$ & $5.6(0.2)$ & 98 & 0.66 & $5.8(0.14)$ & $5.7(0.2)$ & 99 & 0.70 \\
\hline \multicolumn{9}{|c|}{$g, m g$ or $\mu g$ per $1000 \mathrm{kcal}$} \\
\hline $\operatorname{sugar}(g)$ & $56.2(0.86)$ & $51.4(1.6)$ & 91 & 0.00 & $55.9(0.93)$ & $54.1(1.2)$ & 97 & 0.24 \\
\hline starch (g) & $66.2(0.71)$ & $73.3(1.2)$ & 111 & 0.00 & $66.9(0.81)$ & $70.4(0.9)$ & 105 & 0.00 \\
\hline fibre $(\mathrm{g})$ & $10.3(0.19)$ & $10.7(0.3)$ & 104 & 0.27 & $10.6(0.20)$ & $12.1(0.3)$ & 114 & 0.00 \\
\hline iron (mg) & $5.8(0.08)$ & $6.1(0.1)$ & 106 & 0.02 & $5.8(0.10)$ & $6.6(0.1)$ & 112 & 0.00 \\
\hline calcium (mg) & $443.2(5.90)$ & $443.7(10.8)$ & 100 & 0.96 & $466.1(8.02)$ & $499.7(10.4)$ & 107 & 0.01 \\
\hline potassium (g) & $1.4(0.0)$ & $1.5(0.0)$ & 111 & 0.00 & $1.4(0.0)$ & $1.7(0.0)$ & 117 & 0.00 \\
\hline magnesium (mg) & $132.9(1.69)$ & $136.3(3.0)$ & 103 & 0.30 & $131.1(1.95)$ & $146.7(2.7)$ & 112 & 0.00 \\
\hline phosphate (mg) & $643.7(6.56)$ & $687.1(12.1)$ & 107 & 0.00 & $657.2(8.57)$ & $738.7(11.0)$ & 112 & 0.00 \\
\hline copper $(\mathrm{mg})$ & $0.6(0.02)$ & $0.6(0.0)$ & 105 & 0.43 & $0.6(0.02)$ & $0.7(0.0)$ & 115 & 0.01 \\
\hline zinc (mg) & $4.6(0.06)$ & $5.0(0.1)$ & 110 & 0.00 & $4.6(0.07)$ & $5.2(0.1)$ & 114 & 0.00 \\
\hline iodine $(\mathrm{mg})$ & $95.8(1.65)$ & $109.3(5.5)$ & 114 & 0.00 & $100.2(2.17)$ & $106.7(2.7)$ & 107 & 0.06 \\
\hline vitA $(\mu \mathrm{g})$ & $645.7(53.36)$ & $612.6(61.5)$ & 95 & 0.72 & $682.1(69.32)$ & $693.2(72.9)$ & 102 & 0.91 \\
\hline vitD $(\mu \mathrm{g})$ & $2.1(0.07)$ & $2.4(0.2)$ & 115 & 0.08 & $1.8(0.06)$ & $2.3(0.1)$ & 128 & 0.00 \\
\hline vitE (mg) & $4.6(0.12)$ & $4.5(0.2)$ & 97 & 0.59 & $4.7(0.14)$ & $4.8(0.2)$ & 103 & 0.54 \\
\hline $\operatorname{vitC}(\mathrm{mg})$ & $34.2(1.02)$ & $36.4(1.7)$ & 107 & 0.26 & $38.6(1.63)$ & $47.1(2.0)$ & 122 & 0.00 \\
\hline thiamin (mg) & $0.8(0.01)$ & $0.9(0.0)$ & 112 & 0.00 & $0.8(0.01)$ & $0.9(0.0)$ & 118 & 0.00 \\
\hline ribofl $(\mathrm{mg})$ & $0.9(0.02)$ & $1.0(0.0)$ & 105 & 0.16 & $1.0(0.02)$ & $1.1(0.0)$ & 113 & 0.00 \\
\hline niacin (mg) & $16.3(0.18)$ & $18.9(0.4)$ & 116 & 0.00 & $16.4(0.23)$ & $19.2(0.4)$ & 117 & 0.00 \\
\hline vitB6 (mg) & $1.1(0.01)$ & $1.2(0.0)$ & 112 & 0.00 & $1.1(0.02)$ & $1.3(0.0)$ & 118 & 0.00 \\
\hline vitB12 $(\mu \mathrm{g})$ & $3.2(0.19)$ & $3.3(0.2)$ & 106 & 0.60 & $3.0(0.20)$ & $3.2(0.2)$ & 104 & 0.64 \\
\hline folate $(\mu \mathrm{g})$ & $137.6(2.13)$ & $150.2(4.2)$ & 109 & 0.00 & $138.5(2.73)$ & $158.0(3.8)$ & 114 & 0.00 \\
\hline biotin $(\mu \mathrm{g})$ & $17.1(0.26)$ & $16.9(0.5)$ & 99 & 0.72 & $16.9(0.32)$ & $18.0(0.5)$ & 107 & 0.04 \\
\hline pantoth (mg) & $2.6(0.03)$ & $2.9(0.1)$ & 111 & 0.00 & $2.6(0.04)$ & $3.0(0.1)$ & 116 & 0.00 \\
\hline
\end{tabular}

*100×(LER/non-LER) - average percentage of non-LER intake reported by LERs. 
both sexes. For the micronutrients examined, energy adjusted intakes of all minerals and vitamins were higher among female LERs than non-LERs, significantly so for seven of eight minerals and 9 of 12 vitamins. Among men, intakes of all minerals and 9 of 12 vitamins were higher among LERs, significantly so for five minerals and five vitamins. The largest differences in micronutrient intake were observed in vitamins $\mathrm{D}$ and $\mathrm{C}$ among women, and vitamin $\mathrm{D}$ and niacin in men. These results refer only to micronutrient intake from food and drink as supplements were not included in the analysis.

\section{Discussion}

The UK National Diet and Nutrition Survey of people aged over 65 years was affected to a large extent by low energy reporting. In the free living sample $48 \%$ of women and $29 \%$ of men were classified as LERs. Using a comparable cut off $(1.1 \times$ BMR $)$ LERs comprised $21 \%$ of the sample studied by Price. ${ }^{5}$ In the NDNS of the younger $16-64$ year old adults, $46 \%$ of women and $29 \%$ of men were classified as LERs despite using a cut off value of $1.2 \times$ $\mathrm{BMR},{ }^{3}$ a similar cut off with the elderly would increase the LERs to $61 \%$ of women and $41 \%$ of men. The levels observed among the free living subjects were considerably higher than those observed among those living in institutions (19\% men, $19 \%$ women).

There are several possible explanations for the reporting of low energy intakes by participants in dietary surveys. The survey period may coincide by chance with a period of low energy intake, however the probability of this effect causing the number of LERs observed here is extremely small when using a stringent cut off value. Alternatively, participants may have changed their diet during the period of the survey, but again the cut off value used here makes this an unlikely explanation for the large numbers of LERs observed. The primary reason for low energy reporting in this survey is most likely to have been incomplete recording of food intake.

Weighed food diaries are potentially the most accurate way to measure food intake, ${ }^{9}$ however their completion requires greater effort than other dietary survey methods and this has previously been found to present a barrier. In assessing the accuracy of weighed diaries Livingstone ${ }^{10}$ reported that snack foods were most likely to be missed. While the weighed diary methodology may be a factor here it would not explain why this survey was so much more affected than the previous NDNS of younger adults, unless snack consumption is a larger feature of the elderly diet. Poorer memory should not have been an issue as all subjects completed memory tests before being given food diaries, those failing being given assistance. Increased errors in food weighing may be a factor, although such errors would be expected to be unbiased with over-reading as probable as under-reading.

The NDNS of younger adults was carried out eight years before this survey. Hirvonen ${ }^{6}$ compared low energy reporting in two similar studies carried out 10 years apart. The prevalence of low energy reporting rose from $27 \%$ to $42 \%$ among men and from $33 \%$ to $46 \%$ among women, increases of a similar magnitude to those seen when comparing the two NDNS surveys. ${ }^{3}$ The rise was attributed to increased health consciousness and a reluctance to report consumption of foods known to be unhealthy. This effect may have been a further contributory factor to the low energy reporting observed here. A further possibility is that the observed increases in low energy reporting result from decreasing energy requirements, however evidence from elderly UK women suggests that this is not the case. ${ }^{11}$

The suitability of equations used to define a low energy reporter must also be questioned. Calculation of the BMR used the Schofield equations, ${ }^{7}$ the derivation of which included only small numbers of elderly subjects. The equations also assume a linear relation between body weight and BMR, as fat tissue is less metabolically active this seems likely to be an oversimplification. While verification of the equations is required urgently, they continue to be the most suitable for an elderly European population and inaccuracies are unlikely to be the sole cause of the large numbers of LERs observed here.

As with other studies of low energy reporting, women were more likely than men to be classified as LERs. ${ }^{356}$ This may partly be attributable to women obtaining higher percentages of energy from fat than men, while fat is most affected by low energy reporting, however the difference between men and women was small (36.2\% women, $35.3 \%$ men; $\mathrm{p}=0.02$ ), and would not explain the large difference in LER prevalence. Health consciousness, which is thought to be higher among women, may also be a factor.

Obesity was most strongly associated with LER status in both men and women, in agreement with other studies. ${ }^{356}$ This could be the result of the linear relation assumed by the Schofield equations between BMR and body weight, which as already mentioned seems likely to be an oversimplification. Significant univariate associations were observed between LER status and both education and social class, however results from a multivariate analysis were less clear and differed from those of other studies. Hirvonen ${ }^{6}$ observed that LERs were more likely to be highly educated in a group of 16-64 year olds, while Price ${ }^{5}$ found no effect of current social class in a cohort of people born in 1946. The only significant association we found in a multivariate model was with social class among men. This suggests social class is more important than education among older populations while the reverse may be true in younger groups.

Food groups in which LERs reported lower intakes than non-LERs included full fat dairy products, sugar and sweet foods, and alcoholic drinks. Interestingly, they also reported lower intakes of fruit and nuts, wholemeal bread and wholemeal cereals, the differences in alcohol consumption were also greater for wine and spirits than for beer. This could indicate that 
two effects are observed when comparing the food intakes of LERs and non-LERs, one being a tendency to under-report mostly those foods that are known to be unhealthy, the other being true dietary differences associated with the socioeconomic characteristics of the two groups. Few studies have compared food intakes of LERs and non-LERs but a similar pattern was reported from the NDNS of British adults. ${ }^{3}$

Absolute intakes of all macronutrients were significantly lower among LERs, as seen elsewhere. ${ }^{3512}$ Comparison of nutrient densities gave results broadly consistent with those of other studies: protein was higher among LERs $^{35^{12}}$; total fat was lower ${ }^{512}$; total carbohydrate did not differ significantly ${ }^{5}$ but sugar was lower ${ }^{3}$ and starch higher ${ }^{3}$; alcohol was lower. ${ }^{3} \mathrm{~A}$ further study by Hirvonen ${ }^{6}$ also found higher densities of protein and carbohydrate and lower densities of fat among LERs, but results of significance tests directly comparing the two groups were not reported.

Low energy reporting causes major problems in the interpretation of dietary data. The probability of a single factor causing the level of low energy reporting observed in this survey is extremely small. Rather it is probable that several factors coalesced, these being primarily a tendency to omit certain items from weighed diaries, a reluctance to report foods known to be unhealthy, and possibly a weakness in the definition of elderly LERs. By adjusting for energy intake the effect of low energy reporting is reduced in analyses of both food and nutrient intakes, although as food groups are not uniformly affected this is not a complete solution. Validatory biomarkers such as doubly labelled water provide a more complete answer to the problem and would have been particularly useful in this survey given the scale of low energy reporting that took place.

Funding: this work was funded by a grant from the Ministry of Agriculture, Fisheries and Foods.

Conflicts of interest: none.

1 Black AE, Prentice AM, Goldberg GR, et al. Measurements of total energy expenditure provide insights into the validity of dietary measurements of energy intake. $7 \mathrm{Am}$ Diet Assoc 1993;93:572-9.

2 Black AE, Goldberg GR, Jebb SA, et al. Critical evaluation of energy intake data using fundamental principles of energy physiology: 2. Evaluating the results of published surveys. Eur 7 Clin Nutr 1991;45:583-99.

3 Pryer JA, Vrijheid M, Nichols R, et al. Who are the 'Low energy reporters' in the dietary and nutritional survey of British adults? Int 7 Epidemiol 1997;26:146-54.

4 Bingham SA. Validation of dietary assessment through biomarkers. In: Kok FJ, van't Veer P, eds. Biomarkers of dietary exposure. London: Smith-Gordon, 1991:41-52.

5 Price GM, Paul AA, Cole TJ, et al. Characteristics of the low energy reporters in a longitudinal dietary survey. Brf Nutr 1997;77:833-51

6 Hirvonen T, Männistö S, Roos E, et al. Increasing prevalence of underreporting does not necessarily distort dietary surveys. Eur 7 Clin Nutr 1997;51:297-301. 7Dietary reference values for food energy and nutrients for the United Kingdom. London: HMSO, 1991.

8 Goldberg GR, Black AE, Jebb SA, et al. Critical evaluation of energy intake data using fundamental principles of energy physiology: 1. Derivation of cut-off limits to identify under-recording. Eur $\mathcal{F}$ Clin Nutr 1991;45:569-81.

9 Bingham SA. The dietary assessment of individuals; methods, accuracy, new techniques and recommendations. mutrition abstracts and reviews 1987;57:705-42.

10 Livingstone MBE, Prentice AM, Strain JJ, et al. Accuracy of weighed dietary records in studies of diet and health. BMf 1990;300:708-12.

11 Reilly JJ, Lord A, Bunker VW, et al. Energy balance in healthy elderly women. Br f Nutr 1993;69:21-7.

12 Voss S, Kroke A, Klipstein-Grobusch, et al. Is macronutrient composition of dietary intake data affected by underreporting? Results from the EPIC-Potsdam study. Eur $\mathcal{F}$ Clin Nutr 1998;52:119-26. 